\title{
LOVE IS ONE OF THE REASONS STUDENTS COMMUNICATE: STUDY ABOUT MOTIVE COMMUNICATION AND RELATIONAL SATISFACTION STUDENTS
}

\author{
Sri Wahyuning Astuti, Atwar Bajari, Atie Rachmiatie, Antar Venus \\ ${ }^{1}$ Sri Wahyuning Astuti,,Mercu Buana University. E-mail: sri.wahyuning.astuti@mercubuana.ac.id \\ ${ }^{1}$ Atwar Bajari, Padjajaran University. E-Mail: atwarbajari@unpad.ac.id. \\ ${ }^{1}$ Atie Rachmiatie, Bandung Islamic University. E-mail:atierachmiatie@unisba.ac.id \\ ${ }^{1}$ Antar Venus, Padjadjaran University. E-mail: Antarvenus@unpad.ac.id
}

\begin{abstract}
Millennials are the generation that has the largest number of Indonesia's total population. There are inconsistencies with millennial studies in their interpersonal communication skills and communication satisfaction. Therefore, this study tested whether there was an influence on millennial students' communication motives and communication satisfaction. The respondents in this study were 969 consisting of 523 women and 446 men who are the millennial category in the 14-18 years range and sit in class 10 of Senior High School. This study uses a quantitative approach with data collection using a scale of communication motivations and interpersonal relationship satisfaction. The results showed a relationship between communication motives and communication satisfaction, besides producing a high pleasure motive. Research also shows that millennials' need for love is relatively high. This research indicates that the desire to get recognition, love, and affection from the environment is still very high.
\end{abstract}

Keywords:

communication motives, students, communication satisfaction

Article Received: 18 October 2020, Revised: 3 November 2020, Accepted: 24 December 2020

\section{INTRODUCTION}

Students who go about their days studying at school need a conducive atmosphere to get optimal results from their school learning process. The favorable atmosphere among them is obtaining by balanced communication between students and teachers, students, and students and the school environment that supports the teaching and learning process.

The success of communication made by students, in addition to motivating them to complete their studies, can also be a means to transfer thoughts. Effective communication plays an essential role in building the character and standard of student education. Students who feel comfortable communicating will naturally produce satisfaction in their interpersonal relationships.

There are many motives for communication. The motive in communicating is how and why people do interpersonal communication. Rubin, in 1988, first revealed this concept. According to him, the interpersonal communication motive is chosen in the conscious condition, when someone communicates. Because it is carrying out the communication agent's full awareness, the interpersonal communication motive is relatively stable, which means that the reason chosen in conducting the communication is following each communication agent [1]

Rubin said there are six motives in communicating: pleasure, affection, inclusion, escape, relaxation, and control. Each individual is undoubtedly different in choosing their communication motives, depending on the level of satisfaction obtained. Individuals who feel comfortable with communication try to build a relationship for the sake of seeking pleasure.

Furthermore, they communicate as an expression of affection with others. Communication can also be a means to exercise control over others. People will more easily control others through qualified communication skills and convey ideas to ask people to do things according to their wants.

The choice of communication motives by individual communication actors, resulting in communication satisfaction, raises interpersonal 
relationships even at an advanced level. Individuals who are satisfied with interpersonal relationships modifiers have passed the phase of excellent communication. Satisfaction in living relationships, among others, is formed from how they communicate with others.

Several studies mention that effective communication between students and teachers can improve student success directly [2]. Not only that, but several studies also suggest the relationship between students and teachers is not only limited to the learning process but also how both of them understand each other can obtain by the success of communication between the two [3]. Research conducted in several schools in Saudi Arabia states that a friendly environment and the success of communication, both verbal and nonverbal, in a school environment has a positive effect on increasing student learning motivation at school.

In conducting communication, students have their motives. The choice of reasons is indeed base on what satisfaction they will get when communicating. William C. Schutz mentions that communication is generally base on interpersonal needs, which consist of three categories: inclusion, control, and affection. Inclusion refers to the need to maintain satisfying relationships with others and have sufficient involvement and ownership; control related to the need for influence and power; and compassion, friendship, closeness, and love [4]. Every person's interpersonal needs are different. Awareness of individual, interpersonal needs will enable us to understand their communication behavior better.

In addition to increasing motivation in completing studies, students' communication also raises feelings of happiness because they can share and exchange ideas and thoughts. Feelings of joy, a sense of belonging, and affection from someone who communicates bring satisfaction in their interpersonal relationships. Heeman in his research, mentioned that young women who have communication satisfaction with their fathers have satisfaction in their interpersonal relationships. Interpersonal relationships that have become more positive correlation because of the communication satisfaction [5]

Similar research results from Hecth (1987) also mentioned that establishing communication satisfaction has a close relationship with self and others. Individuals who are satisfied with themselves means having high self-confidence in undergoing interpersonal relationships with others [6]. Not only that, but individuals who are confident with their condition also have selfesteem and positive self-concepts. Generally, those who have a positive self-concept can establish positive interpersonal relationships with others. A good self-concept also makes it easier for individuals to accept others, making it easier to develop others' interactions. Davis proves that students' self-confidence and independence help build their relationships with their teachers through nonverbal communication [7].

Encouragement of students in communicating with others or called interpersonal communication motives, usually has specific characteristics. One reason for linking connection with the motive for communicating is that the motivation for talking to others is inseparable from who, how, or what we talk about with someone. This combination of construction represents the components needed for an interaction to take place. For example, a motive for communication cannot exist regardless of the partner or with whom he interacts, how to communicate, and the subject or topic that is the subject of conversation [8].

One of the main assumptions from this perspective is that people are aware of their communication choices and that people's choices are goals and objectives directed towards giving rise to satisfaction. Six interpersonal communication motives have been identified to explain some of the most common reasons people choose to engage in communication: pleasure, affection, inclusion, escape, relaxation, and control. This theory offers an ideal framework for knowing why and how one interpersonal communication [1].

Fun reflects entertainment motives, and communication is carrying out because it is fun 
and enjoyable. Compassion refers to communication for social rituals and to show respect and care for others. Inclusion is the need to be together and share feelings with others and to reduce loneliness. Escape is communication carried out to avoid carrying out other activities. Relaxation reflects the need to communicate to rest and relax. Control represents communication for instrumental compliance [1].

Students who spend time with the digital world become interesting objects as study material in determining their communication motives. Besides being a shift in communication patterns, the urge to communicate amid the increasing use of technology is also another reason to explore more in-depth about students' motives for interpersonal communication. This research has theoretical and practical goals. This study's academic purpose is to determine the relationship between interpersonal communication motives with student communication satisfaction. At the same time, this study's efficient use is to find a picture of student communication satisfaction.

Therefore, based on the above theory, this research tries to propose a hypothesis, namely:

H0: there is a relationship between interpersonal communication motives with communication satisfaction

$\mathrm{H} 1$ : There is no relationship between interpersonal communication motives and communication satisfaction

\section{Communication Satisfaction}

When explained in the conceptual model, interpersonal communication motives act as independent variables, communication satisfaction as the dependent variable.

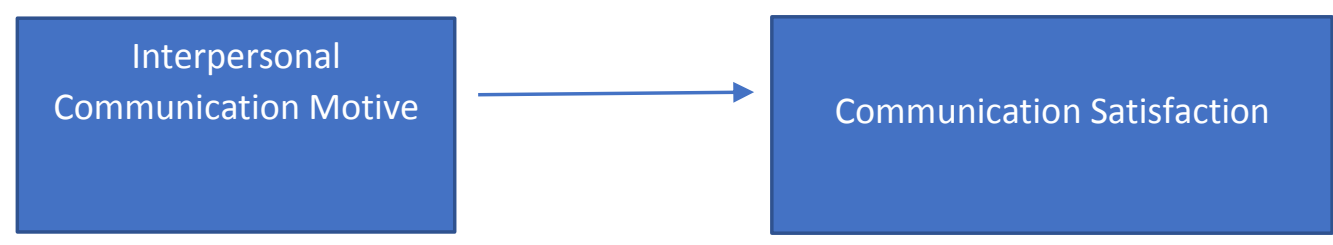

From the picture above, it can be explaining that the communication motives chosen by the generation of students will affect their communication satisfaction.

\section{METHODOLOGY}

The literature review for this study was compiled based on the topic that became the variable in this study, starting from the motive of interpersonal communication, which is an independent variable that affects other variables. Furthermore, the concept of communication satisfaction becomes the dependent variable.

\section{Motives of Interpersonal Communication}

This theory was born from a perspective of people who have a basic need for social interaction and a desire to form the right relationship (Schutz, 1966) [9]. The reason why people talk to each other is a theoretical explanation of the motive for communication. Rubin et al. lay out this conceptual framework. On the theory of Uses Gratification. Simple explanation of this framework is that people have a full awareness of their needs and make conscious choices to meet their needs [1].

In line with Rubin, what was said by Mc Quail also mentioned that the communication motive was an extension of the use of media and gratification. This satisfaction or gratification perspective explains because there is an impetus for someone to choose or use a form of media, intending to gain satisfaction. Likewise, when conducting interpersonal communication, a person has certain motives to satisfy his need to communicate.

The motive for communication was first expressed by Rubin et al., which is explaining as a 
reason for someone's conscious when choosing to have a conversation with another person. The motive for interpersonal communication is considered a relatively stable character about how a person communicates. Rubin et al. further emphasized that the primary key of one's motives in conducting interpersonal communication is the awareness of the communication's communicator, meaning that when going to interpersonal communication, the individual understands the purpose of his communication [1].

Rubin et al. identified six main motives for interpersonal communication in the initial study. A person's motives for interpersonal communication are identifying in 6 categories: pleasure, affection, inclusion, escape, relaxation, and control. Interpersonal communication motives explain why and how one communicates with others. In conducting interpersonal communication, many reasons accompany a person to talk with others. Encouragement of students to communicate with others becomes necessary and vital to know their satisfaction level in communicating [10].

Other motive as part of doing interpersonal communication is motive of inclusion. This motive basically represents the need to still be together with other people as the effort to drive away loneliness. In the meanwhile, someone's effort to drive away boredom is part of escaping when someone do interpersonal communication. Motive of relaxation, as other part of communication motive is the motive to be relaxed and feel cooler, those who do interpersonal communication, commonly want to decrease stress and feel relaxed. While motive of control showed that communication is motivated by someone's need to give instruction to other people and also get the help from other people [10].

Motive of interpersonal communication is the extension from media using and gratification. Perspective of gratification was explained because there is motive in someone to choose or the form of media, with the purpose to gain gratification. And also in doing interpersonal communication, someone has certain motive in fulfilling the need to do communication with other people [11].

In the theory of interpersonal communication motives, admitted that often the choice of people to initiate interpersonal communication is driven by different motives of motifs related to their decision to initiate the interaction Mediated. Also, in many ways, people often rely on interpersonal interactions to fulfill their motives. So in the theory of interpersonal communication motives extends the framework of use and gratification into the context of interpersonal relationships and identifies six interpersonal communication motives of pleasure, affection, inclusion, escapism, relaxation, and control [1].

Results of previous studies revealed that Interpersonal Communication motives on each individual are different and depending on the interfraction situation. The results of the study revealed that ICM varied with demographic traits including Age [12]. Similar research results also reveal the difference in ICM viewed from gender and level of education, men and women have different motives in their communication, likewise with the level of education that is owned by respondents [13].

The selection of communication motifs is also reported to have relationships with one's personality types. Individuals with personality type extroversion, neuroticism, and psychoticism have different effects on the selection of communication motives [14]. The communication environment was also found to affect individual communication motives [15]. Another research that has also been conducted is the connection between the effectiveness of communication with the selection of communication motifs [12]. Not only that, the depth and breadth of communication and the orientation of the conversation also affects the motive in conducting communication [16]

Relational Satisfaction 
Satisfaction: This study identified with a feeling of satisfaction that results from the fulfillment of several needs. Satisfaction is defining as feeling happy or happy. Satisfaction can also be interpreting as feelings that arise when the needs or desires are meeting. Needs and desires can start from simple things such as physical needs such as food and drink, or to more complex needs such as life satisfaction or satisfaction in establishing relationships with others. Thus, satisfaction in communicating is related to how a person chooses interpersonal communication motives. Several previous studies have succeeded in proving the relationship between communication satisfaction and interpersonal communication motives, although the two variables are two different dimensions but have a dependency (Beatty \& Dobos, 1992; Dainton et al., 1994; PunyanuntCarter, 2007b) [17]

Contentment is defined as a feeling of happiness or delight. Satisfaction can also be interpreted as a feeling that arises when a need or a desire is fulfilled. Needs and desires can be initiated from simple things such as physical needs such as food and drink, or up to more complex needs such as life satisfaction or satisfaction in establishing relationships with others. Thus, the satisfaction of communication has an association with how one chooses interpersonal communication motives. Some previous research successfully proved the connection between communication satisfaction and interpersonal communication motives, although both variables were two different dimensions but had dependencies. Communication and relational satisfaction are regarded as a complement of the research of communication motives. Some previous research studies have focused on the relationship between communication and relational satisfaction with communication motives, although they are two distinct dimensions both are competitiveness dependent. Communication and relational satisfaction are often associated with communication motives[18].
Communication satisfaction depends on the view of the communication people about whether their expectations when having conversations with others are fulfilled. In general, communication satisfaction is at a high level when expectations are fulfilled. The hope form usually involves the fulfillment of some types of internal awards that are, strengthening positive ideas, avoiding negative feelings, upholding ideal selfimage, etc.

Relational satisfaction includes someone's view of a relationship. Relational satisfaction also includes a person's perception of their relationship partners with each other. In other words, contentment is a multidimensional concept characterized by communication and relational level of satisfaction [18]. Communication satisfaction is based on the fulfillment of individual positive expectations, and usually offers internal rewards [6]. Meanwhile, relational communications are defined as individual attitudes toward spouses and relationships, usually in the perceived quality terms of the relationship [14]. The satisfaction of communication-related to relational satisfaction [13]

When someone performs communication, there is certainly a desired expectation between the communication actors. When the expectations of communication actors are fulfilled, individuals feel the satisfaction of communication. Communication satisfaction is at a high score if their expectation of communication is fulfilled. The expectation of a person when conducting communication usually revolves around the existence of internal appreciation from the communication actors in the form of strengthening positive ideas and avoiding negative feelings. Meanwhile, the satisfaction of a relationship revolves around the view of the communication perpetrator of the relationship itself. Briefly, the fulfillment is a multidimensional concept characterized by communication and satisfaction level in establishing a relationship [18]

The motive of a person in conducting communications is deemed to be able to explain 
or predict the perception of individual communication with their intrapersonal partners. [19]. The results of the study revealed that people who communicate with others especially for pleasure, inclusion, affection, and relaxation also report higher levels of communication [10]

A pattern of relational communication and satisfaction

The Motif of interpersonal communication is a relationship with the satisfaction of communication. When a person chooses the motive in conducting interpersonal communication, there comes a satisfaction in communicating and establishing interpersonal relationships. The results of previous studies mention that there is a relationship between one's motives in conducting communication with the satisfaction of a conversation [19]

The relationship between

communication motives and communication and relational satisfaction is a researcher's concern. Previous research from Martin et all mentions that communication motifs can often help explain and predict the perception of communication and relational satisfaction with their interlocutor. Communication motifs can explain the communication and relational satisfaction with others that are close interpersonal. This explanation was strengthened by the results of a study conducted by Rubin in 1998 [20] against 504 respondents, which resulted in the finding that people who communicate with others especially for pleasure, inclusion, compassion, and relaxation have Higher communication and relational satisfaction.

Another research also resulted in findings, interpersonal communication motives performed by young adults against their fathers. The findings mentioned that young adult respondents who did communication with control and pleasure motifs had a high level of communication satisfaction with their father. Communication satisfaction is also shown to be high in respondents who choose a pattern of affection and pleasure in their communication [17].

Not only in early adulthood, the level of satisfaction in communication and relational with the selection of communication motifs is also a research material conducted by Punyanunt-Carter [14]. In his research on the communication of young women and their fathers found that communication and relational satisfaction was at the highest level, as the young women chose a communication motif for pleasure. These findings also confirm that the communication performed by the young women with their fathers is generally done for the purpose of affection, pleasure, and relaxation [14]

Communication and relational satisfaction are considering as a complement to the research of communication motives. Although they are two different dimensions, they are interdependent. Communication and relational satisfaction are often associated with communication motives. Communication satisfaction depends on viewpoint communicator about whether their expectations when having a conversation with others have been fulfilling. In general, communication satisfaction is at a high level when expectations are meeting. Forms of hope usually involve the fulfillment of some types of internal rewards, namely, reinforcing positive ideas, avoiding negative feelings, upholding an ideal self-image [18]

When someone communicates, there is certainly hope that is desiring between communication agents. When the expectations of communication actors are meet, then the individual feels communication satisfaction. High scores on communication satisfaction are forme if their expectations when communicating are meet. Expectations when communicating revolve around the existence of internal appreciation from the communicator to reinforce positive ideas and avoid negative feelings. Meanwhile, the satisfaction of a relationship revolves around the viewpoint of the communicator of the relationship itself. Briefly, satisfaction is a multidimensional 
concept characterized by communication and level of satisfaction in establishing a relationship [18].

A person's motives for communicating are considering to explain or predict a person's perception of communication satisfaction with their intrapersonal partners. (Martin \& Anderson, 1995; Punyanunt-Carter, 2005; Rubin et al., 1988) [17]. The results revealed that people who communicate with others, primarily for pleasure, inclusion, affection, and relaxation, also report higher communication satisfaction [1].

\section{Communication Satisfaction}

The motive of interpersonal communication is indicating as correlating with communication gratification. When someone chooses the motive to do interpersonal communication, there appears gratification in communication and interpersonal relationships. Previous research stated that there is a correlation between someone's motive in doing communication with satisfaction in making conversation (Martin \& Anderson, 1995), Punyanunt- Carter, 2005; Rubin et al., 1988) [17]

Gratification is defining as feeling happy or fun. Gratification can also mean the feeling appears when the need or desire is fulfilling. The need and desire can start from simple things like a physical need such as food and drink, or until more complex need like life gratification or gratification in doing relationships with other people. Therefore, gratification in doing communication has a connection with how someone chooses the motive of interpersonal communication. Some previous research proved a correlation between communication gratification and the motive of interpersonal communication, although the two variables are two different variables but have interdependence (Beatty \& Dobos, 1992; Dainton et al., 1994; PunyanuntCarter, 2007b) [17].

When someone is doing communication, there must be a wish between communicators.
When the wish between communicators is fulfilling, the individuals will feel communication gratification. Communication gratification is positioned in the highest score if their wish when doing communication is fulfilling. Someone is a wish when doing communication usually ranges in internal appreciation from the communicator that is strengthening positive ideas and avoiding negative feelings. Simultaneously, the gratification of a relationship ranges from the communicator's perspective about the relationship itself. In summary, satisfaction is a multidimensional concept identified with communication and level of gratification in conducting a relationship.

Someone's motive in doing communication is to explain or predict someone's perception of communication gratification with their interpersonal partnership. (Martin \& Anderson, 1995; Punyanunt-Carter, 2005; Rubin et al., 1988). The result of research revealed that the person who is communicating with other people mainly for pleasure, inclusion, affection, and relaxation also reported a higher level of communication gratification (Rubin et al. 1988) [21].

The motive of Communication and Relational Satisfaction

The relationship between communication motives and communication and relational satisfaction comes to the attention of researchers. Previous research from (Martin \& Anderson, 1995; Punyanunt-Carter, 2005; Rubin et al., 1988) states that communication motives can often explain and predict the communication and relational perceptions of satisfaction with their interlocutors. Communication motives can explain communication and relational satisfaction with other people who are close interpersonal. This explanation is reinforcing by the research results conducted by Rubin (1988) of 504 respondents, which resulted in the finding that people who communicate with others, primarily for pleasure, 
inclusion, compassion, and relaxation, have higher communication and relational satisfaction [21].

Similar research conducted by Martin and Anderson, also produced findings on young adults' interpersonal communication motives towards their fathers. The results state that young adult respondents who communicate with control and pleasure motives have a high level of communication satisfaction with their fathers. Communication satisfaction was also proven to be high in respondents who chose the reason for love and pleasure in their communication [15].

Not only in early adulthood, the level of satisfaction in communicating and relational to the choice of communication motives is also the subject of research conducted by PunyanuntCarter. Their study on the communication of young women and their fathers found that communication and relational satisfaction were at the highest level when young women chose the motive for communication for pleasure. This finding also confirms that communication made by young women and their fathers is generally doing for affection, pleasure, and relaxation [17].

\section{DISCUSSION}

\section{Research design}

This research is a quantitative study to examine the relationship between communication motives with interpersonal communication satisfaction

\section{Participant}

This population sample was high school students in south Jakarta, with a total sample of 969 people consisting of 446 male students and 523 women. The age range of respondents is the age of 14-18 years. All students are digital media users. Measurement
This study uses two measuring instruments, each of which is to measure the variables studied, the two measuring devices are:

The scale of Motifs of communication

To measure communication motives are used from Rubin et al. The original scale consists of 28 items based on a Likert scale with an answer range of 1 to 5 , starting from very precise, often, sometimes, rarely to nothing. The scale was then adapted using the Indonesian language and tested on 55 people. Reliability during the trial amounted to 0.887 , with 1 item dropped it item number 27 . Reliability, after the item are eliminate, was eliminated by 0.890 [1]

\section{Communication Satisfaction Scale}

The communication satisfaction scale is operational through two scales, namely the Communication Satisfaction Inventory (Com-Sat) (Hecht, 1978a, 1978b) [6] and the Relational Satisfaction Scale [22]. The communication satisfaction scale consists of 19 items. The relational satisfaction scale consists of 5 items based on a Likert scale with an answer range of 1 to 7, ranging from Strongly Disagree, Moderately Disagree, Slightly Disagree, Undecided, or Neutral, Slightly Agree, Moderately Agree, Strongly Agree. The scale was then adapted using the Indonesian language and tested on 47 people with characteristics similar to the study sample. Reliability for the scale of $(\alpha=.903)$.

After distributing questionnaires to 10 high schools in south Jakarta, 969 respondents obtain the posterior distribution.

Table1: Demographic data of respondents

\begin{tabular}{llll}
\hline Descriptive & & frequency & Percentage \\
\hline Sex & Female & 523 & 54,0 \\
& Male & 446 & 46,0 \\
Age & 14 & 21 & 2,2 \\
& 15 & 263 & 27,1 \\
& 16 & 469 & 48,4 \\
& 17 & 193 & 19,9
\end{tabular}




\section{8}

23

2,4

Based on the data above, the number of respondents between men and women has a range

that is not too far away, while most student respondents are in the age range of 16 years.

Tabel 2

Exposure to the use of digital media

\begin{tabular}{llll}
\hline Descriptive & & Frequency & Percentage \\
\hline $\begin{array}{l}\text { Kind of Smartphone } \\
\text { used }\end{array}$ & Android & 655 & 67,6 \\
& Iphone & 298 & 30,8 \\
& Blackberry & 11 & 1,1 \\
& Android and Iphone & 3 & 0,2 \\
& Others & 2 & 0,3 \\
& Total & 969 & 100 \\
Time to acess Internet & Less than 3 hours & 79 & 8,2 \\
& 3-5 hours & 311 & 32,1 \\
& 5-10 hours & 458 & 47,3 \\
& More than 10 hours & 118 & 12,2 \\
& Never & 3 & 3 \\
Social Media Used & Total & 969 & 100 \\
& Facebook & 35 & 3,6 \\
& Twitter & 29 & 3,0 \\
& Instagram & 859 & 88,6 \\
& Path & 2 & 0,2 \\
& Line & 31 & 3,2 \\
& Whats up & 0,6 & 0,6 \\
& Youtube & 0,2 & 0,2 \\
& Others & 0,5 & 0,5 \\
& Total & 969 & 100 \\
\hline
\end{tabular}

Average student uses a smartphone with the Android operating system as many as 655 people, followed by the iPhone as many as 298 people, and the rest use two smartphones at once or use a blackberry.

Analysis to test hypotheses using SPSS AMOS and to check the validity and reliability of test kits. The reliability measurement also shows that this study's items are reliable with their respective reliability values for communication motives of 0.975 and communication satisfaction of 0.973 (table

Tabel 3: reliability

\begin{tabular}{lll}
\hline & CR & AVE \\
\hline Communication Motive & 0,975 & 0,959 \\
Satisfaction Relationship & 0,973 & 0,941 \\
\hline
\end{tabular}

Tabel 4: Correlation of laten variabel 


\begin{tabular}{lll}
\hline & $\begin{array}{l}\text { Communication } \\
\text { motive }\end{array}$ & $\begin{array}{l}\text { Satisfaction } \\
\text { Relationship }\end{array}$ \\
\hline Communication motive & 1 & \\
Satisfaction Relationship &, 425 & 1 \\
\hline
\end{tabular}

Tabel 6 Hypothesis Testing: Summary Result

\begin{tabular}{lllll}
\hline Hypotheses & Relationship Being Examined & Cooeficient & SE & P Value \\
\hline $\mathrm{H} 1_{\mathrm{a}}$ & There is correlation between 10,090 &, 032 & $* * *$ \\
& Communication motive, with & & & \\
& communication gratification & & &
\end{tabular}

The next step is to calculate the magnitude of the correlation between each variable and test the hypothesis. The explanation for the extent of the correlation value in table 7

Tabel 7: Correlation Value

\begin{tabular}{rrrr}
\hline & & \multicolumn{2}{c}{ Estimate } \\
\hline Satisfaction Relationship & $<--$ & Communication Motive &, 308 \\
\hline
\end{tabular}

Table 7 above explains that the Motive of Communication contributes to relational satisfaction with a standardized regression coefficient of 0.308 and $p<0.01$. Furthermore, Communication Motive plays a role in Psychological Well Being with a standardized regression coefficient of -0.023 and $p<0.01$, while
Relational Satisfaction plays a direct role in behavior with standardized regression coefficients of 0.480 and $p>0.01$.

Meanwhile, the dependent variable's useful contribution to the independent variable is explain in the following table.

Tabel 8: R Square value

\begin{tabular}{ll}
\hline & Estimate \\
\hline Satisfaction Relationship & .095
\end{tabular}

Based on the data above, the active contribution of the Communication Motive to Relational Satisfaction is $0.095(9.5 \%)$.

Tabel 9: Description of Communication Motives

\begin{tabular}{|l|l|l|}
\hline Communication Motive & Mean & Standar deviation \\
\hline pleasure & 31.48 & 4,99 \\
\hline Affection & 19.97 & 3,40 \\
\hline Inclusion & 14,74 & 3,48 \\
\hline Escape & 10,35 & 3.38 \\
\hline Relaxation & 15.07 & 3,24 \\
\hline Control & 5,72 & 2,00 \\
\hline
\end{tabular}


Based on the table above, students' motives for communicating are looking for fun, followed by affection and relaxation.

\section{DISCUSSION}

Satisfaction in communication is the main thing that has a positive effect on students. Besides improving, this research is the first research in Indonesia, trying to see the relationship between communication motives and student communication satisfaction.

Students as a generation who are familiar with technology and use almost all of their daily activities with the digital world make them have poor communication patterns [23]. That is because most of the time, they are used with smartphones to change communication patterns. This study tries to find a picture of students' communication motives when communicating with others and their level of satisfaction when communicating.

The real motive for interpersonal communication is the extension of the gratification of the use of mass media. It means that in choosing a motivation for communication, adjusted for the possibility of gratification to be obtained [4]. When students select the motive for communication, there is hope that satisfaction will be receiving. The results revealed a relationship between the choice of interpersonal communication motives with their communication satisfaction [5]. Individuals in this case who have satisfaction in their interpersonal communication, reportedly also experienced an increase in their interpersonal relationships. Research produced by Barnett et al., Et al. States that young women who have positive interpersonal relationships with their fathers also experience satisfaction in their communication [24]

The results of the above research, researchers also see the importance of describing the motives and communication satisfaction of students. In addition to motivating them to achieve at school, satisfaction in establishing communication will enhance positive relationships with teachers, friends, and parents. The average student in this study has an age range of 14-18 years or is in the millennial age range. Following the task of adolescent development Ericson, in the age range of 14-18 years, emotionally adolescents are inadequacy; that is, they need love, affection, appreciation, and sympathy from others [25].

For students, communication satisfaction and satisfaction in establishing relationships with others are influenced not only by the real world but also by the virtual world. It happens because the lives of students are inseparable from digital technology. Extension of interaction space to the digital world certainly has consequences for students. The desire to always be the same as what seen in cyberspace makes students experience a decrease in interpersonal relationships, including anxiety, and not establishing relationships in the real world. Positive interactions in the real world are reduced both in intensity and quality. Consequently, students are in an isolated condition [26]

This study produces interesting findings following empirical evidence be testing, namely the first that there is a significant relationship between interpersonal communication motives with student communication satisfaction. It means that the reason someone is communicating brings them to relationship satisfaction and communication. The next finding that is also interesting to note is base on the mean results of the students' primary motives for interpersonal communication is for reasons of affection, followed by relaxation. It means that most students engage in interpersonal communication because of reasons for seeking pleasure.

\section{Conclusion}

Under the task of developing adolescents who are still looking for identity and need love, students need social support from the environment. Forms of support can include intensifying directional communication between students, both parents 
and teachers, and peers. The success of communication that students have is expecting to increase self-confidence and improve their achievement in school.

\section{Refferences}

[1] A. M. Rubin, M. M. Martin, and R. B. Rubin, "Interpersonal communication motives," Commun. Personal. Trait Perspect., no. January 1998, pp. 287-307, 1998, [Online]. Available: c:\%5CDocuments and Settings\%5CAngel\%5CDesktop\%5CAngel_ Backup\%5CEndNote\%5CTemplates\%5CCan cer ACS.dot.

[2] M. C. Mabaso, "the Influence of Rewards on Job Satisfaction and," no. January, pp. 1-291, 2017.

[3] M. Jamail and Y. Don, "Gen-Y Teacher Leadership on Conflict Management and Communication Satisfaction," Int. J. Acad. Res. Bus. Soc. Sci., vol. 9, no. 1, pp. 881-897, 2019, doi: 10.6007/ijarbss/v9-i1/5488.

[4] A. M. Rubin and R. B. Rubin, "Interface of personal and mediated communication: A research agenda," Crit. Stud. Mass Commun., vol. 2, no. 1, pp. 36-53, 1985, doi: $10.1080 / 15295038509360060$.

[5] C. V. Heeman, "Interpersonal communication motives, satisfaction, and psychological well being in father-young adult daughter relationships. .," 2008.

[6] P. J. Hecth, M. L., \& Marston, "Communication satisfaction and the temporal development of conversations.," Commun. Res. Reports, vol. 4, no. (2), pp. 60-65., 1987.

[7] T. C. Davis et al., "Childhood vaccine risk/benefit communication in private practice office settings: a national survey.," Pediatrics, vol. 107, no. 2, 2001, doi: 10.1542/peds.107.2.e17.

[8] E. E. Graham, C. A. Barbato, and E. M. Perse, "The Interpersonal Communication Motives Model," Commun. Q., vol. 41, no. 2, pp. 172-186, 1993, doi: 10.1080/01463379309369877.
[9] M. M. Step and M. O. Finucane, "Interpersonal communication motives in everyday interactions," Commun. Q., vol. 50, no. 1, pp. 93-109, 2002, doi: 10.1080/01463370209385648.

[10] R. B. Rubin and A. M. Rubin, "Antecedents of Interpersonal Communication Motivation," Commun. Q., vol. 40, no. 3, pp. 305-317, 1992, doi: 10.

[11] McQuail 's Mass Communication Theory. .

[12] S. Sun, G. Hullman, and Y. Wang, "Communicating in the multichannel age: Interpersonal communication motivation, interaction involvement and channel affinity," J. Media Commun. Stud., vol. 3, no. 1, pp. 7-15, 2011.

[13] R. Geometry and G. Analysis, "Interpersonal communication motives satisfaction, and psychological well-being in father-young adult daughter relationships," Dep. Bioteknol. - Sekol. Tinggi Ilmu Pengetah. - Univ. Baghdad. Baghdad, Irak, vol. 49, no. Jurnal Sains Irak, pp. 1-12, 2008.

[14] Z. I. Zara and Z. I. Zara, "Interpersonal communication motives satisfaction, and psychological well-being in father-young adult daughter relationships," Guă nlǐ xiàndàihuà, pp. 61-64, 2008.

[15] M. M. Martin and C. M. Anderson, "The Father-Young Adult Relationship: Interpersonal Motives, Self-Disclosure, and Satisfaction," Commun. Q., vol. 43, no. 2, pp. 119-130, 1995, doi: 10.1080/01463379509369963.

[16] C. A. Barbato, E. E. Graham, and E. M. Perse, "Interpersonal communication motives and perceptions of humor among elders Interpersonal Communication Motives and Perceptions of Humor Among Elders," no. October 2014, pp. 37-41, doi: 10.1080/08824099709388644.

[17] N. M. Punyanunt-Carter, "Father and daughter motives and satisfaction," Commun. Res. Reports, vol. 22, no. 4, pp. 293-301, 2005, doi: 10.1080/000368105000317573.

[18] M. J. Beatty and J. A. Dobos, “Adult Sons' 
Satisfaction with Their Relationships with Fathers and Person-Group (Father) Communication Apprehension," Commun. Q., vol. 40, no. 2, pp. 162-176, 1992, doi: $10.1080 / 01463379209369831$.

[19] M. M. Martin, "Development of a Measure of Interpersonal Communication Competence," Commun. Res. Reports, vol. 11, no. 1, pp. 33-44, 1994, doi: 10.1080/08824099409359938.

[20] R. C. Barnett, N. Kibria, G. K. Baruch, and J. H. Pleck, "Adult Daughter-Parent Relationships and Their Associations with Daughters' Subjective Well-Being and Psychological Distress," J. Marriage Fam., vol. 53, no. 1, p. 29, 1991, doi: 10.2307/353131.

[21] R. B. Rubin, E. M. Perse, and C. Barbato, "Conceptualization and Measurement o f Interpersonal Communication Motives," Hum. Commun. Res., vol. 14, no. 4, pp. 602628, 1988.

[22] R. Norton, "Measuring Marital Quality : A Critical Look at the Dependent Variable," vol. 45, no. 1, pp. 141-151, 1983.

[23] Hole, Y., \& Snehal, P. \& Bhaskar, M. (2018). Service marketing and quality strategies. Periodicals of engineering and natural sciences, 6 (1), 182-196.

[24] Hole, Y., \& Snehal, P. \& Bhaskar, M. (2019). Porter's five forces model: gives you a competitive advantage. Journal of Advanced Research in Dynamical and Control System, 11 (4), 1436-1448.

[25] Yogesh Hole et al 2019 J. Phys.: Conf. Ser. 1362012121

[26] Usihana., “Generasi milenial 'gagap' komunikasi tatap muka.," https://lifestyle.kompas.com/read/2017/04/06/ 061200720/generasi.milenial.gagap.komunik asi.tatap.muka/ 27 Agustus 2018, 2017. .

[27] R. G. Barnett, “Adult daughter-parents relationship and their associations with dauhgters' subjective well-being and psychological distres. Journal of Marriage and Family.," J. Marriage Fam., vol. 53 (1), pp. 29-42., 1991.

[28] M. M. Calvin S. Hall, Gardner Lindzey, John C. Loehlin, Introduction to Theories of Personality. Wiley, 1985.

[29] S. W. Astuti, "Hubungan Antara Pemilihan Media Konvergensi Smartphone Dengan Alienasi Sosial Pada Mahasiswa Universitas Mercu Buana Relationship Between Selection of Smartphone Convergence Media with Social Alienation At Universitas Mercu Buana Abstraksi Smartphone menj," no. 1, pp. 1-16, 2018. 